\title{
Micrografting of Protea cynaroides
}

\author{
H. C. Wu ${ }^{1}$, E. S. du Toit ${ }^{1}$ and C. F. Reinhardt ${ }^{1}$
}

(1) Department of Plant Production and Soil Science, Faculty of Natural and Agricultural Sciences, University of Pretoria, Pretoria, 0002, South Africa

\section{Abstract}

The inability to induce rooting of in vitro-established Protea cynaroides microshoots has prevented the production of complete plantlets. A successful shoot-tip micrografting technique was developed using in vitro-germinated $P$. cynaroides seedlings as rootstocks and axenic microshoots established from pot plants as microscions. Thirty-day old seedlings, germinated on growth-regulator-free, half-strength Murashige and Skoog medium, were decapitated and a vertical incision made from the top end. The bottom ends of microshoots established on modified Murashige and Skoog medium were cut into a wedge ('V') shape, and placed into the incision. The micrografted explants were cultured in a growth chamber with the temperature adjusted to $25 \pm 2{ }^{\circ} \mathrm{C}$, with a $12-\mathrm{h}$ photoperiod. Best results were obtained by placing the microscions directly onto the rootstock without any pre-treatments. Dipping the explants in anti-oxidant solution or placing a layer of medium around the graft area led to the blackening of the microscion. Abbreviations EDTA Ethylenediaminetetraacetate - BAP 6-Benzylaminopurine - $G A_{3}$ Gibberellic acid - PAR Photosynthetic active radiation

\section{Introduction}

Protea cynaroides, known as the King Protea, is endemic to South Africa. It is an important cutflower in the local and export market. In vitro propagation is commonly used to mass-produce disease-free plantlets that take a long time to grow under conventional vegetative propagation methods. In vitro propagation of $P$. cynaroides has had limited success. In vitro establishment (Ben-Jaacov and Jacobs 1986; Wu and du Toit 
2004) and in vitro multiplication (Wu 2001) have been reported. However, in vitro rooting of these microshoots has not been achieved. Conventional in vitro rooting methods, such as the addition of various rooting hormones into the growth media, have not been successful in inducing microshoots to form roots. A reason for this may be due to the fact that Protea spp. are known to be inherently difficult to root. Furthermore, phenolic exudates and the slow growth of microshoots further affect its ability to form roots (Thimmappaiah Puthra and Anil 2002).

Micrografting is mostly used for obtaining virus-free plants, separating viruses in infections, breeding specific genotypic combinations, and for studying graft incompatibility between scions and rootstocks (Burger 1985; Navarro 1988). Other uses that have also been investigated include: rejuvenation of adult avocados by graftage onto juvenile rootstocks (Pliego-Alfaro and Murashige 1987) and germplasm exchange in cashew (Mantell et al. 1997). In addition, microshoots that are difficult to root, or do not form roots at all in vitro, can be micrografted onto rootstocks to obtain rooted plantlets (Thimmappaiah Puthra and Anil 2002). Several factors affect the success rate of the micrografts. These include the size of the scion, as well as the cultural condition in which the scion was grown (Navarro et al. 1975). In addition, Navarro et al. (1975) reported that using larger scions improved the grafting success rate. Furthermore, using etiolated rootstock seedlings increased the frequency of successful grafts.

Although in vitro micrografting has been reported in many plants such as cashew (Ramanayake and Kovoor 1999; Mneney and Mantell 2001; Thimmappaiah Puthra and Anil 2002), citrus (Navarro et al. 1975; Navarro 1981), pistachio (Abousalim and Mantel 1992), prickly pear cactus (Estrada-Luna et al. 2002) and Prunus spp. (Deogratias et al. 1986), micrografting of Protea spp. has yet to be achieved. The aim of this study was to develop a micrografting technique suitable for $P$. cynaroides through which rooted genetically uniform plantlets could be produced in vitro. 


\section{Materials and methods}

In vitro-germinated seedlings were used as the rootstock. $P$. cynaroides seeds were first surface-sterilized in $0.35 \%$ sodium hypochlorite $(\mathrm{NaOCl})$ for $5 \mathrm{~min}$ and then for $3 \mathrm{~min}$ in concentrated sulphuric acid $\left(\mathrm{H}_{2} \mathrm{SO}_{4}\right)$. Afterwards, the seeds were stirred in sterilized distilled water for $10 \mathrm{~min}$. The embryo was then removed from the seed by opening the seed coat. The embryos were carefully placed into the medium, in an upright position. Half-strength Murashige and Skoog (MS) medium (Murashige and Skoog 1962) was used as the growth medium. The embryos were germinated in a growth chamber with a 12 -h photoperiod and the temperature was adjusted to $25 \pm 2^{\circ} \mathrm{C}$. Cool, white fluorescent tubes provided $60 \mu \mathrm{mol} \mathrm{m} \mathrm{m}^{-2} \mathrm{PAR}$. Germination of the embryos were observed after 30 days in culture (Fig. 1A).
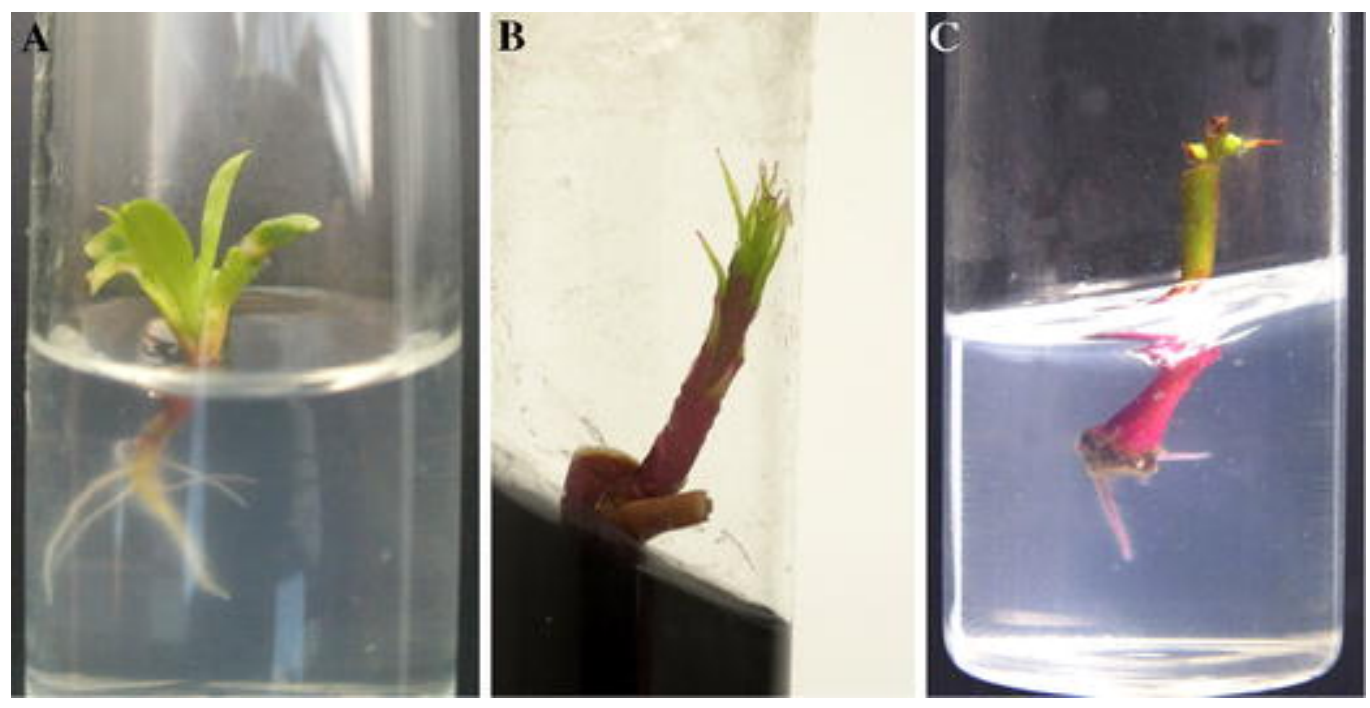

Fig. 1 (A) Roots of 30-day old in vitro-germinated P. cynaroides seedling were used as rootstock; (B) Thirty-day old sprouted axillary bud on established nodal explant was used as microscion; (C) Growth of axillary buds and roots on micrografted plantlet

To obtain sterile microscions, microshoots, which sprouted from axillary nodes of in vitro-established nodal explants, were used. In order to induce the sprouting of the microshoot on the nodal explants, the in vitro establishment of $P$. cynaroides nodal explants was done according to $\mathrm{Wu}$ and du Toit (2004): Shoot segments were taken from 1-year old P. cynaroides plants grown in black plastic bags in a greenhouse (Greenhouse 
temperature: $\left.22-25^{\circ} \mathrm{C}\right)$. After removing the leaves, the explants $( \pm 1 \mathrm{~cm}$, containing one to two nodes) were placed under running water for $2 \mathrm{~h}$. This was followed by dipping them into $70 \%$ ethanol for $10 \mathrm{~s}$ and in $0.35 \%$ sodium hypochlorite for $6 \mathrm{~min}$. Afterwards, the explants were stirred in filter-sterilized antioxidant solution containing $100 \mathrm{mg} \mathrm{l}^{-1}$ ascorbic acid and $1500 \mathrm{mg} \mathrm{l}^{-1}$ citric acid for $1 \mathrm{~h}$. The explants were then placed onto the establishment medium consisting of half-strength MS medium (including vitamins) supplemented with sucrose $\left(20 \mathrm{~g} \mathrm{l}^{-1}\right)$, activated charcoal $\left(3 \mathrm{~g} \mathrm{l}^{-1}\right)$, EDTA $\left(50 \mathrm{mg}^{-1}\right)$ and Gelrite $^{\circledR}\left(3 \mathrm{~g}^{-1}\right)$. Additional growth regulators such as $\mathrm{GA}_{3}\left(30 \mathrm{mg} \mathrm{l}^{-1}\right)$, BAP $\left(2 \mathrm{mg} \mathrm{l}^{-1}\right)$ and myo-inositol ( $100 \mathrm{mg} \mathrm{l}^{-1}$ ) were also added into the medium. The $\mathrm{pH}$ of the medium was adjusted to 5 using $\mathrm{KOH}$ before autoclaving. The explants were placed in a growth chamber with a 16 -h photoperiod and temperature of $25 \pm 2{ }^{\circ} \mathrm{C}$. Cool, white fluorescent tubes provided $60 \mu \mathrm{mol} \mathrm{m} \mathrm{s}^{-2} \mathrm{PAR}$. After 30 days, the sprouted axillary bud was removed from the nodal explant, and prepared to be used as the microscion (Fig. 1B). Micrografting was done by grafting the microscion onto the in vitro-germinated seedlings. Ten 30-day old seedlings (Fig. 1A) were decapitated, and a $2 \mathrm{~mm}$ vertical incision was made from the top of each rootstock. Ten microscions were prepared by cutting the microshoots (Fig. 1B) evenly into $5 \mathrm{~mm}$ length, and each bottom end into a wedge ('V') shape. The microscion was then quickly and firmly placed into the vertical incision of the rootstock. The micrografted explants were cultured in a growth chamber with the temperature adjusted to $25 \pm 2{ }^{\circ} \mathrm{C}$, with a 12-h photoperiod.

Due to the tendency of the newly-grafted explants turning black because of phenolic oxidation, three treatments were applied to the microscions, namely: (1) untreated, (2) soaking the microscions in $100 \mathrm{mg} \mathrm{l}^{-1}$ ascorbic acid and $150 \mathrm{mg} \mathrm{l}^{-1}$ citric acid for $10 \mathrm{~min}$, and (3) placing a layer of solidified half MS medium around the graft area. Ten grafts were made in each treatment using almost uniform microscions and rootstocks. The number of successful grafts was recorded after 2 weeks in culture. The experiment was repeated twice. Data from the second experiment are reported in this paper. Data were analyzed with the Chi-square analysis method in the SAS programme (SAS Institute Inc 1996). 


\section{Results}

Micrografting success was determined by whether the graft union formed or not, and the subsequent growth of the bud on the microscion. The ability of the graft unions to form successfully varied from 10 to $80 \%$ between the three treatments (Table 1). The success rate of the untreated (control) microscions was significantly higher $(p \leq 0.01)$ than the other two treatments, with $80 \%$ of the graft unions forming after 2 weeks. After the formation of the graft union, terminal and axillary buds on the microscion began to swell and expand. After 8 weeks, sprouting of the buds was observed, which attained lengths of up to $5 \mathrm{~mm}$ with 3 leaves (Fig. 2). Desiccation of microscions of the remaining control micrografts was the result of poor contact between microscion and rootstock.

Table 1 Effects of pre-treatments on grafting success, indicated by the formation of graft union and the growth of buds

\begin{tabular}{|l|l|}
\hline Treatment & Grafting success (\%) \\
\hline Control & $80 \mathrm{a}$ \\
\hline Antioxidant Pre-treatment ${ }^{1}$ & $10 \mathrm{~b}$ \\
\hline Medium application at graft area $^{2}$ & $10 \mathrm{~b}$ \\
\hline
\end{tabular}

\footnotetext{
${ }^{1}$ Ascorbic acid (100 $\left.\mathrm{mg} \mathrm{l}^{-1}\right)$ and citric acid $\left(150 \mathrm{mg} \mathrm{l}^{-1}\right)$

${ }^{2}$ Half-strength MS medium

Percentages followed by different letters are significant at $p \leq 0.01$ according to Chisquare
} 

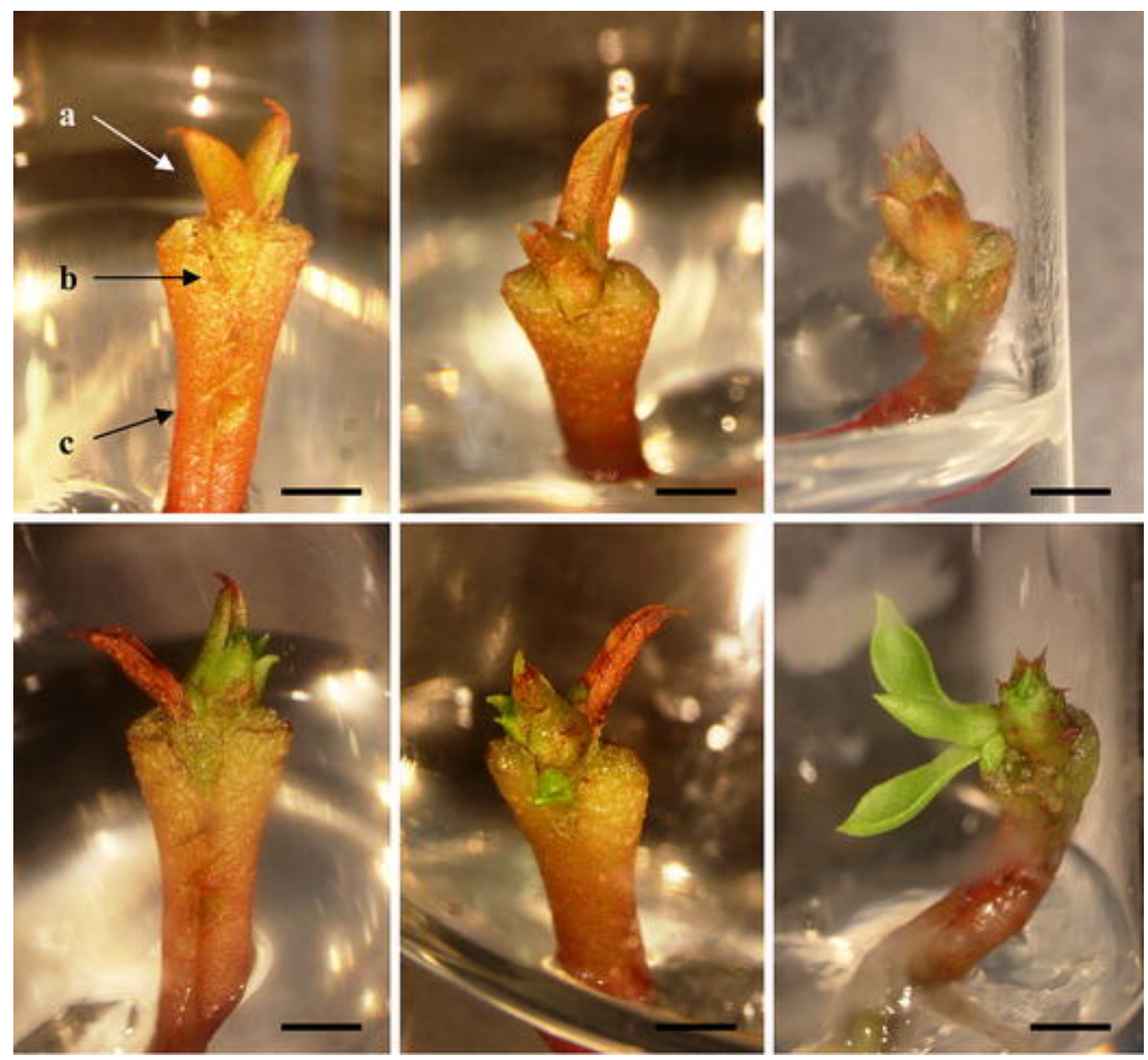

Fig. 2 Top row: Formation of the graft union after 2 weeks in culture. Bottom row: Sprouting of terminal and axillary buds on microscion after 8 weeks. a, microscion; $b$, graft union of wedge-shaped ('V') incision; c, rootstock. Bar $\approx 5 \mathrm{~mm}$

In the two treated micrografts, wetness of microscion and the graft area caused the failure of the graft union to form. Only one graft union of each of the other two treatments formed successfully. However, due to excessive wetness of the microscions from the pretreatments and the medium applied around the graft area, the entire microscion soon turned brown and died.

\section{Discussion}

Jonard et al. (1983), Edriss and Burger (1984) and Starrantino and Caruso (1988) increased the number of successful micrografts by pre-treating the microscion with 
hormonal solutions or anti-oxidants. In addition, Thimmappaiah Puthra and Anil (2002) reported that dipping the microscion in anti-browning solution (ascorbic acid and citric acid) reduced phenolic browning and drying of the cashew microscions. Pliego-Alfaro and Murashige (1987) applied a layer of moist nutrient agar at the graft area to prevent drying of the microscion, which improved the formation of the graft unions in avocados. In contrast, Ponsonby and Mantell (1993) reported that by applying antioxidants or medium solution to the graft area significantly reduced graft union successes. They proposed that this might have been due to excessive moisture created by the applied solutions, which caused the dilution of substances responsible for the establishment of a functional graft union.

In $P$. cynaroides micrografts, soaking the microscions in pre-treatment solutions, or applying a layer of medium to the graft area only aggravated the tissue blackening. Instead, best results were obtained when clean, dry, untreated microscions were used. This is in agreement with Navarro (1988) who reported that fast operation during micrografting was more effective in avoiding phenolic oxidation than using antioxidants. The wetness caused by the antioxidant and nutrient-agar treatments promoted the spread of phenolic oxidation from the graft area to the rest of the explant. A possible reason for the lack of inhibition of phenolic oxidation by the antioxidant solution may be the use of insufficient concentrations of ascorbic and citric acids. It is likely that the amount of phenolic compounds found in P. cynaroides is considerably higher than those found in cashew microscions, since the concentrations of ascorbic acid $\left(100 \mathrm{mg}^{-1}\right)$ and citric acid (150 $\mathrm{mg} \mathrm{l}^{-1}$ ) used in this study was identical to that used by Thimmappaiah Puthra and Anil (2002) in micrografting cashew plantlets, with the soaking period twice as long.

Furthermore, the results of this study showed that the application of a layer of moist nutrient agar around the graft area to prevent dehydration of the microscion and rootstock was not necessary, since the rate at which the graft union formed was quick enough to heal the wounds and prevent moisture loss. This is despite the finding that a moisture film at the graft area was beneficial in conventional grafting (Hartmann et al. 1997). 
The firm placement of the microscion onto the rootstock to ensure good contact was essential for the formation of the graft union. Only one dislocation of the microscion occurred in the control treatment, while the majority of the microscions were able to establish vascular connection with the rootstock as indicated by wound callus formation in the 2 nd week. It has been reported that the formation of callus is a good indication of grafting success, since the callus provides the initial pathway for water until vascular connections are formed between the rootstock and scion (Hartmann et al. 1997).

Dislocation of the micrograft resulted in drying-out of the microscion, in which no callus formation was observed. Dislocation of the microscion has also been reported as a cause of micrografting failures in cashew (Ramanayake and Kovoor 1999).

The micrografting success rate of the untreated $P$. cynaroides microscions $(80 \%)$ achieved in this study is relatively high, in comparison to $30-50 \%$ success rates in micrografting of Citrus explants (Navarro et al. 1975), and success rates of up to $85 \%$ were obtained when Citrus microscions were pre-treated in kinetin solution (Edriss and Burger 1984). The growth-regulator-free half-strength MS medium was ideal for the growth of the micrografts. New roots formed simultaneously with the opening and growth of the bud after 8 weeks (Fig. 1C and 2).

\section{Conclusion}

Micrografting of $P$. cynaroides was successful by using dry microscions and roostocks. In addition, ensuring good contact between the microscion and the rootstock was essential for the graft unions to form successfully. The micrografting method reported in this paper can be used to obtain well-rooted, disease-free microshoots within 60 days. Furthermore, this technique can be adopted in breeding of specific genotypes or other species that are difficult to root. For future studies, the use of higher antioxidant concentrations is needed to determine the optimal concentrations for the prevention of phenolic oxidation. In addition, the study of acclimatization of micrografted $P$. cynaroides explants in ex vitro conditions is needed. 


\section{References}

Abousalim A, Mantel SH (1992) Micrografting of pistachio (Pistacia vera cv. Mateur). Plant Cell Tiss Org Cult 29:231-234.

Ben-Jaacov J, Jacobs G (1986) Establishing Protea, Leucospermum and Serruria in vitro. Acta Hort 185:39-52.

Burger DW (1985) Micrografting: a tool for the plant propagator. Comb Proc Int Plant Prop Soc 34:244-248.

Deogratias JM, Lutz A, Dosba F (1986) In vitro micrografting of shoot-tips from juvenile and adult (Prunus avium (L.) and Prunus persica (L.). Acta Hort 193:139-145.

Edriss MH, Burger DW (1984) Micro-grafting shoot-tip culture of Citrus on three trifoliate rootstocks. Sci Hort 23:255-259.

Estrada-Luna AA, López-Peralta C, Cárdenas-Soriano E (2002) In vitro micrografting and the histology of graft union formation of selected species of prickly pear cactus (Opuntia spp.). Sci Hort 92:317-327.

Hartmann HT, Kester DE, Davies FT Jr, Geneve RL (1997) Plant Propagation: Principles and Practices, 6th edn. Prentice Hall, New Jersey, USA.

Jonard R, Hugard J, Macheix J-J (1983) In vitro micrografting and its application to fruit science. Sci Hort 20:147-159.

Mantell SH, Boggetti B, Bessa AMS, Lemos EP, Abdelhadi A, Mneney EE (1997) Micropropagation and micrografting methods suitable for international transfers of cashew. Proc Intl Cashew and Coconut Conference, Dar es Salaam, Tanzania 
Mneney EE, Mantell SH (2001) In vitro micrografting of cashew. Plant Cell Tiss Org Cult 66:49-58.

Murashige T, Skoog F (1962) A revised medium for rapid growth and bioassays with tobacco tissue cultures. Physiol Plant 15:473-497.

Navarro L (1981) Citrus shoot-tip grafting in vitro (STG) and its applications: A review. Proc Int Soc Citr pp 452-456.

Navarro L (1988) Application of shoot-tip grafting in vitro to woody species. Acta Hort $227: 43-55$.

Navarro L, Roistacher CN, Murashige T (1975) Improvement of shoot-tip grafting in vitro for virus-free citrus. J Am Soc Hort Sci 100:471-479.

Pliego-Alfaro F, Murashige T (1987) Possible rejuvenation of adult avocado by graftage onto juvenile rootstocks in vitro. HortScience 22:1321-1324.

Posonby DJ, Mantell SH (1993) In vitro establishment of Picea pungens f. glauca and P. sitchensis seedling rootstocks with an assessment of their suitabilities for micrografting with scions of various Picea species. J Hort Sci 68(4):463-475.

Ramanayake SMSD, Kovoor A (1999) In vitro micrografting of cashew (Anacardium occidentale L.). J Hort Sci Biotech 74(2):265-268.

SAS Institute Inc (1996) The SAS system for Windows. SAS Institute Inc. SAS Campus drive, Cary, North Carolina, USA.

Starrantino A, Caruso A (1988) The shoot-tip grafting technique applied to citriculture. Acta Hort 227:101-103. 
Thimmappaiah, Puthra GT, Anil SR (2002) In vitro grafting of cashew (Anacardium occidentale L.). Sci Hort 92:177-182.

Wu HC (2001) Micropropagation of Protea cynaroides L. Master's thesis. Department of Plant Production and Soil Science, University of Pretoria, Pretoria, South Africa.

Wu HC, du Toit ES (2004) Reducing oxidative browning during in vitro establishment of Protea cynaroides. Sci Hort 100:355-358. 